\title{
Sedimentary Organic Matter and Phosphate along the Kapuas River (West Kalimantan, Indonesia)
}

\author{
Pei Sun Loh, ${ }^{1}$ Chen-Tung Arthur Chen, ${ }^{2}$ Gusti Z. Anshari, ${ }^{3}$ Jiann-Yuh Lou, ${ }^{4}$ \\ Jough-Tai Wang, ${ }^{5}$ Shu-Lun Wang, ${ }^{6}$ and Bing-Jye Wang ${ }^{2}$ \\ ${ }^{1}$ Department of Marine Sciences, Ocean College, Zhejiang University, Hangzhou, China \\ ${ }^{2}$ Department of Oceanography, National Sun Yat-Sen University, Kaohsiung, Taiwan \\ ${ }^{3}$ Soil Science Department, Universitas Tanjungpura, Pontianak, Indonesia \\ ${ }^{4}$ Department of Marine Science, Republic of China Naval Academy, Kaohsiung, Taiwan \\ ${ }^{5}$ Department of Atmospheric Sciences and Graduate Institute of Atmospheric Physics, National Central University, \\ Chungli, Taiwan \\ ${ }^{6}$ Department of Marine Environment Engineering, College of Ocean Engineering, National Kaohsiung Marine University, \\ Kaohsiung, Taiwan
}

Correspondence should be addressed to Pei Sun Loh; psloh@hotmail.com

Received 29 June 2016; Accepted 4 September 2016

Academic Editor: Stanislav Frančišković-Bilinski

Copyright (c) 2016 Pei Sun Loh et al. This is an open access article distributed under the Creative Commons Attribution License, which permits unrestricted use, distribution, and reproduction in any medium, provided the original work is properly cited.

\begin{abstract}
This study assessed the sedimentary organic matter $(\mathrm{OM})$ and phosphate along the world's longest river on an island: the Kapuas River in West Kalimantan, Indonesia. The surface sediment was tested using the loss-on-ignition experiment to determine the \% labile $\mathrm{OM}, \%$ refractory $\mathrm{OM}$, and \% total $\mathrm{OM}$ and the $\mathrm{Rp}$ values (the ratio of refractory to total $\mathrm{OM}$ ). The $\mathrm{C} / \mathrm{N}$ ratios and the inorganic phosphate (IP), organic phosphate (OP), and total phosphate (TP) levels were also determined. The combination of high $\mathrm{Rp}$ values and low $\mathrm{C} / \mathrm{N}$ ratios along the upper river indicated the possible presence of relatively degraded material; the low $\mathrm{Rp}$ values and high $\mathrm{C} / \mathrm{N}$ ratios downstream were indicative of a fresher terrestrial signal. Sedimentary P levels were the highest along the densely populated areas downstream from the Kapuas River; the second highest along the midstream river, which is surrounded by oil palm plantations; and the lowest along the upper river, which is surrounded by forest. Higher levels of OM, IP, OP, and TP downstream along the Kapuas River indicated the presence of anthropogenic sources of OM and P.
\end{abstract}

\section{Introduction}

Rivers are major regulators of global climate change due to their role as contributors to atmospheric $\mathrm{CO}_{2}$ emissions $[1,2]$. Rivers, in turn, are greatly affected by global climate change and are consequently at risk [3]. For instance, increased temperatures affect the hydrological cycles of rivers worldwide [4], increasing river runoff in some regions of the world while reducing river runoff in other regions $[5,6]$. One of the consequences of increasing river runoff is increased nutrient discharge to coastal zones. This has a significant impact, particularly in areas that were already receiving a high input of nutrients from their surroundings [7]. Human activities such as urbanization and deforestation have resulted in an increase in the amount of soil organic matter released into rivers by erosion. However, building reservoirs has decreased the amount of sediment discharged into rivers and coastal zones and altered the timing of sediment discharge. In Indonesia, where there are few reservoirs, rivers still deliver a considerable amount of sediment to coastal zones [8]. This has major consequences because Southeast Asia contains a vast area of peatland $[9,10]$, and peat soils tend to leach dissolved organic carbon (DOC) into rivers in quantities several orders of magnitude higher than nonpeat soils do. Consequently, tropical rivers are major sources of DOC to the oceans [11-13]; this leaching is exacerbated by global climate change because increased temperatures [14] and precipitation [15] have resulted in the increased export of DOC from peat soils into rivers and coastal zones. Currently, management 


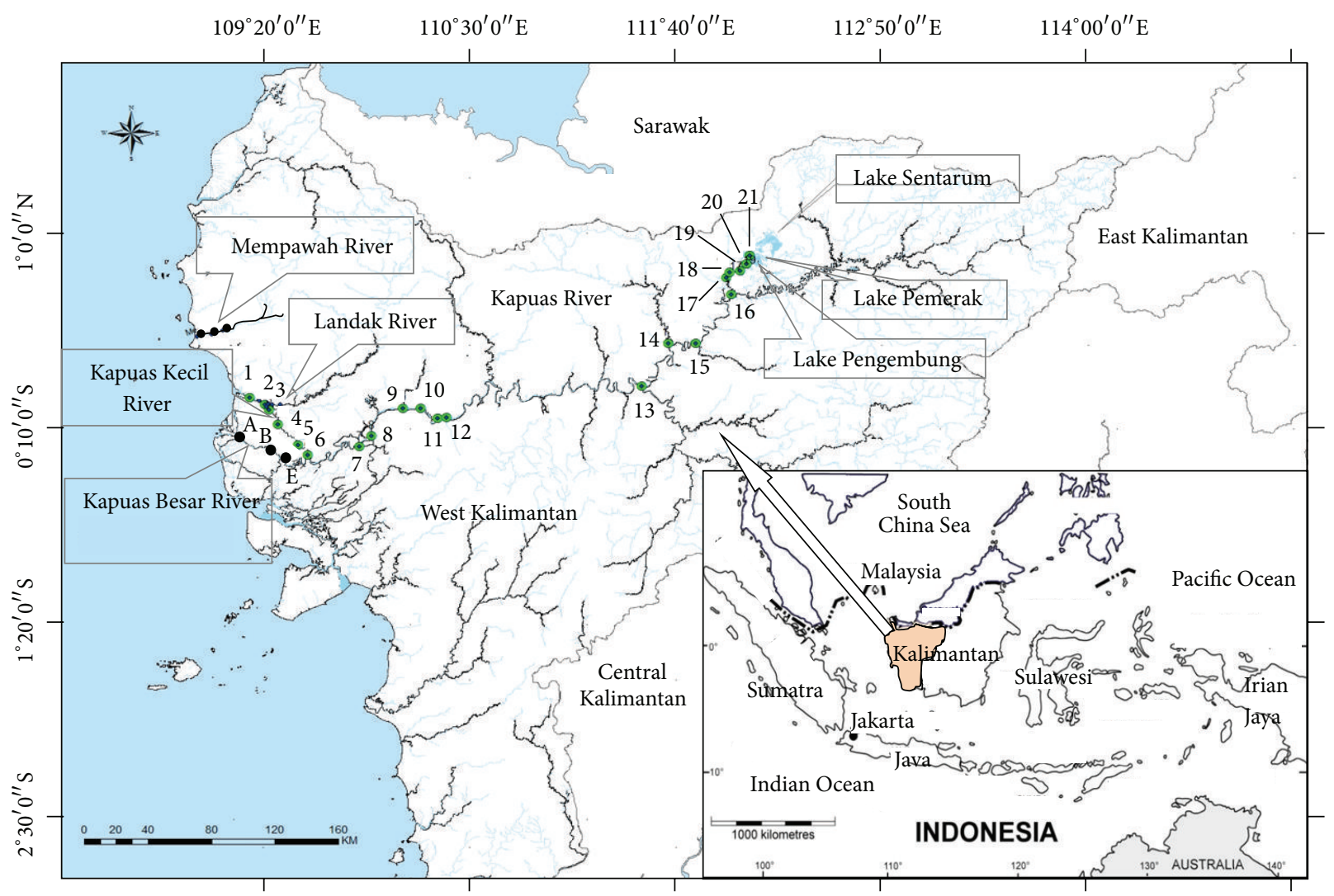

FIgure 1: Map showing the sampling locations along the Kapuas River (which includes the Kapuas Kecil River and Kapuas Besar River), the Mempawah and Landak Rivers, and the Lakes Sentarum, Pemerak, and Pengembung.

strategies to maintain the quality of river and estuary waters are more important than ever $[4,16]$. Knowledge of sediment organic matter (OM) and nutrients along rivers is beneficial for developing these management strategies.

In this study, surface sediments were collected from the Kapuas River, the Landak River, and the Mempawah River and from the three lakes that drain into the Kapuas River. Using the loss-on-ignition experiment, these sediments were tested to determine the \% labile OM, \% refractory OM, and $\%$ total $\mathrm{OM}$ and the $\mathrm{Rp}$ values (the ratio of refractory $\mathrm{OM}$ to total OM). Additionally, inorganic phosphate (IP), organic phosphate (OP), and total phosphate (TP) levels were determined. This study presents a profile of $\mathrm{OM}$ and $\mathrm{P}$ along a Southeast Asian tropical river for the purpose of further understanding the dynamics of the river.

\section{Methods}

2.1. Study Sites. The Kapuas River is located in West Kalimantan, Indonesia. With a length of $1143 \mathrm{~km}$, this is the longest river in Indonesia and the world's longest river on an island. Sampling was carried out from June to July 2007 and December 2007 to January 2008 at the three lakes (Sentarum, Pemerak, and Pengembung) that drain into the upper Kapuas River, at locations spanning the entire extent of the Kapuas River, and at the Landak and Mempawah Rivers. Downstream Kapuas River branches into Kapuas Kecil River and Kapuas Besar River (Figure 1). Sediment was collected by deploying an Eijkelkamp peat sampler from a small boat into a water depth of approximately $2 \mathrm{~m}$. The $0-5 \mathrm{~cm}$ surface sediment was saved for chemical analyses. In the laboratory, the sediment was dried at $60^{\circ} \mathrm{C}$ for a few days, ground using a mortar and pestle, and sieved through a 43-mesh sieve. Details describing the river and sampling locations, including the sampling timetable and distances between the locations and the river mouth, are given by Loh et al. [17, 18]. Detailed information on population densities, wet and dry seasons, and forest types (landscapes) along the Kapuas River, hydrological cycles, and sediment loading have been reported in previous studies $[17,18]$.

2.2. Analytical Method. The loss-on-ignition experiment was compiled from methods used by Kristensen [19], Kristensen and Andersen [20], and Sutherland [21]. A sample of approximately $0.5 \mathrm{~g}$ of dried, ground, and sieved sediment was weighed in a crucible. Crucibles with sediment were weighed and then combusted at $250^{\circ} \mathrm{C}$ for 16 hours in a temperaturemonitored muffle furnace. When cool, the crucibles were reweighed. The sediment was then heated to $500^{\circ} \mathrm{C}$ for 16 hours. When cool, it was weighed again. The percentage of weight reduction after reaching $250^{\circ} \mathrm{C}$ is known as the $\%$ labile organic matter. The percentage of weight loss that occurs within the temperature range between $250^{\circ} \mathrm{C}$ and $500^{\circ} \mathrm{C}$ is the $\%$ refractory $\mathrm{OM}$. The sum of the $\%$ labile and $\%$ 
refractory OM is the \% total OM. The Rp index is the weight loss that occurs in the temperature range between $250^{\circ} \mathrm{C}$ and $500^{\circ} \mathrm{C}$ divided by the total weight loss on ignition; hence, the $\mathrm{Rp}$ value is the ratio of the \% refractory OM to the \% total OM. Kristensen [19] defined Rp as Rp = PII/(PI + PII), where $\mathrm{PI}$ is the weight loss that occurs after combustion in the first temperature range and PII is the weight loss after combustion in the second temperature range.

The method used for phosphate analysis was obtained from Strickland and Parsons [22], Aspila et al. [23], and Koroleff [24]. Dried sediment was weighed to $0.25 \mathrm{~g}$ and washed with $20 \mathrm{~mL}$ of $1 \mathrm{M} \mathrm{HCl}$ in a $50 \mathrm{~mL}$ centrifuge tube. The sediment was extracted with constant shaking for 16 hours at room temperature. On the following day, the supernatant was decanted, and the residue was washed with $5 \mathrm{~mL}$ of $\mathrm{HCl}$, centrifuged, and combined with the supernatant for IP analysis. The residue was transferred to a crucible and heated in a muffle furnace at $550^{\circ} \mathrm{C}$ for two hours. When cool, the residue was transferred to a centrifuge tube and extracted with $25 \mathrm{~mL}$ of $1 \mathrm{~N} \mathrm{HCl}$ for 16 hours at room temperature with constant shaking. The residue was then centrifuged and the supernatant decanted for OP analysis. P was analysed using the molybdenum blue method with a UVvisible spectrophotometer.

For the bulk elemental analysis, the sediment was acidified with $1 \mathrm{~N} \mathrm{HCl}$ overnight to remove carbonates. The sediment was then rinsed with distilled water, dried at $60^{\circ} \mathrm{C}$, and homogenized using a mortar and pestle. Precisely $20 \mathrm{mg}$ of sediment was weighed into a $4 \times 4 \times 11 \mathrm{~mm}$ tin boat and crimped into a pellet. The sediment was analysed for TOC and total nitrogen (TN) using a Vario EL III Elemental Analyzer. The standard reference materials used were BSCC (2.24\% TOC, $0.24 \%$ TN) and NIST2704 (3.34\% TOC, $0.22 \% \mathrm{TN})$. The average coefficients of variation for each measurement (in duplicate and triplicate analyses) of a same-sediment sample were $2.32 \%$ for TOC and $3.08 \%$ for $\mathrm{TN}$. All C/N ratios were calculated as TOC/TN molar ratios.

\section{Results}

Table 1 shows the results obtained for \% labile OM, \% refractory $\mathrm{OM}, \%$ total $\mathrm{OM}, \mathrm{Rp}$ values, IP, OP, and TP. The overall reproducibility was good, with the percentage reproducibility of duplicate and triplicate analyses of \% labile and \% refractory OM ranging from 0.02 to $6.41 \%$. Percentage reproducibility from duplicate analyses of $\mathrm{P}$ ranged from 0.01 to $27.76 \%$. Percentages of labile, refractory, and total OM ranged from 1.61 to $12.19 \%, 2.32$ to $8.70 \%$, and 4.46 to $20.89 \%$, respectively. Both \% labile and \% refractory OM showed a constant range of values along the upper and middle sections of the Kapuas River and showed the highest values downstream of the river (Figures 2(a) and 2(b)). Both the labile and refractory fractions showed good correlations with total OM (Pearson correlation coefficient, $r>0.95$; $p<$ $0.05 ; n=21$ ) for the June to July 2007 sample. Refractory $\mathrm{OM}$ was slightly higher at the upper river and lakes for the December 2007 to January 2008 sample; hence, there was a lower but still significant $(p<0.05)$ correlation between the refractory fraction and labile and total OM during this time. $\mathrm{Rp}$ values (ratio of refractory to total $\mathrm{OM}$ ) ranged from 0.25 to 0.64 , with the highest values observed in the upper river and lakes and the lowest values observed downstream (Figure 2(c)). Rp values showed good negative correlation with total OM $(r>-0.7 ; p<0.05 ; n=21)$. The IP, OP, and TP ranged from 0.03 to $1.55 \mathrm{mg} P / \mathrm{g}, 0.30$ to $0.82 \mathrm{mg} \mathrm{P} / \mathrm{g}$, and 0.40 to $2.37 \mathrm{mg} \mathrm{P} / \mathrm{g}$, respectively. Overall, IP, OP, and TP had similar distribution trends to OM, with slightly higher concentrations at locations downstream than at locations along the upper river (Figure 3). TP showed a better correlation with IP $(r>0.9)$ and a poorer correlation with OP ( $r=0.6$ to 0.8$)$, and IP showed good correlation with labile OM $(p<0.05)$. Overall, the Landak River has the highest labile OM and the Mempawah River has higher Rp values than the Landak River. The Landak River has higher IP, OP, and TP than the Mempawah River (Figures 2 and 3).

\section{Discussion}

4.1. Use of Rp Values and C/N Ratios to Determine the Sources and Diagenesis of Sediment OM. A combination of $\mathrm{Rp}$ values and $\mathrm{C} / \mathrm{N}$ ratios was used to further elucidate the sources and diagenesis of sedimentary $\mathrm{OM}$ along the river. It was found that $\mathrm{Rp}$ values of approximately 0.3 are indicative of plant material rich in carbohydrates, and higher $\mathrm{Rp}$ values of approximately 0.6 are indicative of biogenic material or more degraded OM. Furthermore, humic materials have high $\mathrm{Rp}$ values and $\mathrm{C} / \mathrm{N}$ ratios, and an advanced stage of $\mathrm{OM}$ decomposition was associated with an increase in $\mathrm{Rp}$ values and a decrease in $\mathrm{C} / \mathrm{N}$ ratios. Several scenarios based on these combinations have been observed: (i) low $\mathrm{Rp}$ values and high $\mathrm{C} / \mathrm{N}$ ratios may indicate terrestrial plants as the OM source, (ii) increases in both $\mathrm{Rp}$ values and $\mathrm{C} / \mathrm{N}$ ratios may be indicative of the process of humification, and (iii) high $\mathrm{Rp}$ values and low $\mathrm{C} / \mathrm{N}$ ratios may be indicative of more degraded OM [19]. These combinations were observed along different stretches of the Kapuas River. Scenario (i) occurred at locations 1 through 6 along the lower Kapuas River, which showed lower $\mathrm{Rp}$ values but higher $\mathrm{C} / \mathrm{N}$ ratios, indicating the contribution of fresher plant material. $\mathrm{Rp}$ values in the mid- and lower Kapuas River and the Landak and Mempawah Rivers ranged from 0.39 to 0.48 , also indicating fresher plant material as the source of OM. Scenario (ii) occurred at location 16, which had a high Rp value and a high $\mathrm{C} / \mathrm{N}$ ratio. Scenario (iii) was observed along the upper Kapuas River and in the lakes, which had overall higher Rp values ( 0.59 to 0.64 ) and lower $\mathrm{C} / \mathrm{N}$ ratios; this is indicative of more degraded OM material (Figures 4(a) and 4(b)), consistent with the detection of older peat material along the upper Kapuas River than along the lower Kapuas River [25, 26]. Overall, these results are in accordance with our previous findings that the upper Kapuas River has slightly higher values of vanillic acid/vanillin and syringic acid/syringaldehyde ratios, indicative of more degraded lignin materials, compared to midstream and downstream Kapuas River [17].

4.2. Phosphate in the Sediment of the Kapuas River. The areas surrounding the Kapuas Kecil River were the most populated, followed by the areas surrounding Kapuas Besar. 
TABLE 1: Loss-on-ignition, phosphate, and bulk elemental results.

(a) June-July 2007 sampling

\begin{tabular}{|c|c|c|c|c|c|c|c|c|c|c|}
\hline \multirow{2}{*}{ Loc. } & \multicolumn{4}{|c|}{ Loss on ignition } & \multicolumn{3}{|c|}{ Phosphorus } & \multicolumn{3}{|c|}{ Bulk elemental } \\
\hline & Labile (\%) & Refrac. (\%) & TOM (\%) & $\mathrm{Rp}$ & IP (mg/g) & $\mathrm{OP}(\mathrm{mg} / \mathrm{g})$ & $\mathrm{TP}(\mathrm{mg} / \mathrm{g})$ & $\mathrm{OC}(\%)$ & $\mathrm{TN}(\%)$ & $\mathrm{C} / \mathrm{N}$ \\
\hline KB1 (A) & $6.83 \pm 0.00$ & $5.22 \pm 0.02$ & 12.05 & 0.43 & $0.63 \pm 0.01$ & $0.63 \pm 0.01$ & 1.26 & 3.04 & 0.19 & 18.67 \\
\hline KB2 (B) & $7.70 \pm 0.01$ & $4.94 \pm 0.03$ & 12.64 & 0.39 & $0.62 \pm 0.00$ & $0.62 \pm 0.00$ & 1.24 & 3.22 & 0.20 & 18.78 \\
\hline KB3 (E) & $6.10 \pm 0.04$ & $4.42 \pm 0.04$ & 10.52 & 0.42 & $0.62 \pm 0.00$ & $0.39 \pm 0.11$ & 1.01 & 2.72 & 0.16 & 19.83 \\
\hline 1 & $8.96 \pm 0.07$ & $5.81 \pm 0.03$ & 14.77 & 0.39 & $0.78 \pm 0.00$ & $0.62 \pm 0.00$ & 1.40 & 5.04 & 0.24 & 24.50 \\
\hline 2 & $8.60 \pm 0.02$ & $6.52 \pm 0.01$ & 15.12 & 0.43 & $1.55 \pm 0.02$ & $0.82 \pm 0.05$ & 2.37 & 5.11 & 0.30 & 19.87 \\
\hline 3 & $12.19 \pm 0.07$ & $8.70 \pm 0.08$ & 20.89 & 0.42 & 1.12 & 0.78 & 1.90 & 8.88 & 0.44 & 23.55 \\
\hline 4 & $8.52 \pm 0.26$ & $5.32 \pm 0.16$ & 13.84 & 0.38 & $0.63 \pm 0.01$ & $0.63 \pm 0.01$ & 1.26 & 4.69 & 0.22 & 24.87 \\
\hline 5 & $6.93 \pm 0.02$ & $5.21 \pm 0.03$ & 12.14 & 0.43 & $0.62 \pm 0.00$ & $0.55 \pm 0.11$ & 1.17 & 3.32 & 0.20 & 18.67 \\
\hline 6 & $4.62 \pm 0.01$ & $3.77 \pm 0.02$ & 8.39 & 0.45 & $0.47 \pm 0.00$ & $0.47 \pm 0.00$ & 0.94 & 2.11 & 0.12 & 20.51 \\
\hline 7 & $5.63 \pm 0.09$ & $5.07 \pm 0.07$ & 10.70 & 0.47 & $0.63 \pm 0.00$ & $0.55 \pm 0.11$ & 1.18 & 2.47 & 0.16 & 15.17 \\
\hline 8 & $5.92 \pm 0.05$ & $5.52 \pm 0.03$ & 11.44 & 0.48 & $0.47 \pm 0.00$ & $0.62 \pm 0.01$ & 1.09 & 2.51 & 0.19 & 15.41 \\
\hline 9 & $6.69 \pm 0.04$ & $4.97 \pm 0.02$ & 11.66 & 0.43 & $0.62 \pm 0.01$ & $0.62 \pm 0.01$ & 1.24 & 3.11 & 0.20 & 18.14 \\
\hline 10 & $3.06 \pm 0.04$ & $2.71 \pm 0.01$ & 5.77 & 0.47 & $0.39 \pm 0.12$ & $0.31 \pm 0.00$ & 0.70 & 1.36 & 0.08 & 19.83 \\
\hline 11 & $5.22 \pm 0.00$ & $3.67 \pm 0.06$ & 8.89 & 0.41 & $0.32 \pm 0.00$ & $0.47 \pm 0.00$ & 0.79 & 2.28 & 0.13 & 20.46 \\
\hline 12 & $4.13 \pm 0.02$ & $3.45 \pm 0.01$ & 7.58 & 0.46 & $0.46 \pm 0.01$ & $0.31 \pm 0.00$ & 0.77 & 1.92 & 0.11 & 20.36 \\
\hline 13 & $5.49 \pm 0.02$ & $3.74 \pm 0.03$ & 9.23 & 0.41 & $0.63 \pm 0.00$ & $0.47 \pm 0.00$ & 1.10 & 2.63 & 0.15 & 20.46 \\
\hline 14 & $5.61 \pm 0.06$ & $3.89 \pm 0.09$ & 9.50 & 0.41 & $0.63 \pm 0.00$ & $0.47 \pm 0.00$ & 1.10 & 2.77 & 0.15 & 21.54 \\
\hline 15 & $6.56 \pm 0.03$ & $4.45 \pm 0.04$ & 11.01 & 0.40 & $0.62 \pm 0.01$ & $0.55 \pm 0.12$ & 1.17 & 3.22 & 0.21 & 17.89 \\
\hline 16 & $2.24 \pm 0.03$ & $2.32 \pm 0.02$ & 4.56 & 0.51 & $0.47 \pm 0.01$ & $0.31 \pm 0.00$ & 0.78 & 0.86 & 0.05 & 20.07 \\
\hline 17 & $3.30 \pm 0.62$ & $4.66 \pm 0.61$ & 7.96 & 0.59 & $0.31 \pm 0.00$ & $0.46 \pm 0.00$ & 0.77 & 1.94 & 0.17 & 13.31 \\
\hline 18 & $2.91 \pm 0.09$ & $4.29 \pm 0.01$ & 7.20 & 0.60 & $0.16 \pm 0.00$ & $0.16 \pm 0.00$ & 0.32 & 0.59 & 0.08 & 8.60 \\
\hline 19 & $2.65 \pm 0.02$ & $4.21 \pm 0.02$ & 6.86 & 0.61 & $0.32 \pm 0.00$ & $0.32 \pm 0.00$ & 0.64 & 0.62 & 0.09 & 8.04 \\
\hline 20 & $1.61 \pm 0.02$ & $2.85 \pm 0.03$ & 4.46 & 0.64 & $0.16 \pm 0.00$ & $0.31 \pm 0.00$ & 0.40 & 0.55 & 0.06 & 10.69 \\
\hline 21 & $2.59 \pm 0.01$ & $3.80 \pm 0.01$ & 6.39 & 0.59 & $0.31 \pm 0.00$ & $0.47 \pm 0.00$ & 0.51 & 1.04 & 0.12 & 10.11 \\
\hline LK1 & $20.76 \pm 0.16$ & $6.81 \pm 0.22$ & 27.57 & 0.25 & $0.93 \pm 0.00$ & $0.62 \pm 0.00$ & 1.55 & 14.20 & 0.55 & 30.12 \\
\hline LK2 & $16.35 \pm 0.01$ & $7.00 \pm 0.02$ & 23.35 & 0.30 & $0.31 \pm 0.01$ & $0.47 \pm 0.01$ & 1.41 & 8.96 & 0.30 & 34.84 \\
\hline LK3 & $8.05 \pm 0.02$ & $4.56 \pm 0.04$ & 12.61 & 0.36 & $0.47 \pm 0.00$ & $0.47 \pm 0.00$ & 0.94 & 3.84 & 0.17 & 26.35 \\
\hline MH1 & $6.57 \pm 0.01$ & $5.58 \pm 0.03$ & 12.15 & 0.46 & $0.63 \pm 0.01$ & $0.31 \pm 0.01$ & 0.94 & 2.90 & 0.13 & 26.03 \\
\hline MH2 & $3.92 \pm 0.54$ & $3.54 \pm 0.52$ & 7.46 & 0.47 & - & - & - & 1.80 & 0.07 & 30.00 \\
\hline MH3 & $3.76 \pm 0.17$ & $3.99 \pm 0.23$ & 7.75 & 0.51 & - & - & - & 1.47 & 0.06 & 28.58 \\
\hline
\end{tabular}

(b) December 2007-January 2008 sampling

\begin{tabular}{|c|c|c|c|c|c|c|c|c|c|c|}
\hline \multirow{2}{*}{ Loc. } & \multicolumn{4}{|c|}{ Loss on ignition } & \multicolumn{3}{|c|}{ Phosphorus } & \multicolumn{3}{|c|}{ Bulk elemental } \\
\hline & Labile (\%) & Refrac. (\%) & TOM (\%) & $\mathrm{Rp}$ & IP (mg/g) & $\mathrm{OP}(\mathrm{mg} / \mathrm{g})$ & $\mathrm{TP}(\mathrm{mg} / \mathrm{g})$ & OC (\%) & $\mathrm{TN}(\%)$ & $\mathrm{C} / \mathrm{N}$ \\
\hline$\overline{\mathrm{KB} 1(\mathrm{~A})}$ & - & - & - & - & $0.52 \pm 0.00$ & $0.61 \pm 0.03$ & & - & - & - \\
\hline KB2 (B) & - & - & - & - & $0.64 \pm 0.01$ & $0.11 \pm 0.00$ & & - & - & - \\
\hline KB3 (E) & - & - & - & - & $0.94 \pm 0.01$ & $0.58 \pm 0.06$ & & - & - & - \\
\hline 1 & $8.66 \pm 0.04$ & $5.37 \pm 0.05$ & 14.02 & 0.38 & $0.75 \pm 0.00$ & $0.50 \pm 0.02$ & 1.24 & 4.84 & 0.30 & 18.8 \\
\hline 2 & $6.08 \pm 0.08$ & $4.38 \pm 0.01$ & 10.45 & 0.42 & $0.72 \pm 0.01$ & $0.50 \pm 0.00$ & 1.22 & 3.90 & 0.23 & 19.8 \\
\hline 3 & $6.59 \pm 0.04$ & $4.36 \pm 0.03$ & 10.95 & 0.40 & $0.73 \pm 0.00$ & $0.49 \pm 0.00$ & 1.22 & 3.49 & 0.23 & 17.7 \\
\hline 4 & $12.95 \pm 0.07$ & $6.76 \pm 0.38$ & 19.71 & 0.34 & $0.23 \pm 0.03$ & $0.35 \pm 0.00$ & 0.58 & 9.24 & 0.35 & 30.8 \\
\hline 5 & $8.88 \pm 0.04$ & $4.85 \pm 0.01$ & 13.73 & 0.35 & $0.61 \pm 0.00$ & $0.44 \pm 0.01$ & 1.05 & 4.22 & 0.27 & 18.2 \\
\hline 6 & $8.83 \pm 0.03$ & $5.26 \pm 0.01$ & 14.09 & 0.37 & $0.74 \pm 0.00$ & $0.49 \pm 0.00$ & 1.23 & 5.01 & 0.30 & 19.5 \\
\hline 7 & $3.65 \pm 0.03$ & $4.72 \pm 0.00$ & 8.37 & 0.56 & $0.30 \pm 0.00$ & $0.42 \pm 0.03$ & 0.72 & 1.43 & 0.17 & 9.8 \\
\hline 8 & $5.49 \pm 0.07$ & $4.42 \pm 0.01$ & 9.91 & 0.45 & $0.40 \pm 0.01$ & $0.40 \pm 0.01$ & 0.80 & 2.47 & 0.20 & 14.4 \\
\hline 9 & $2.74 \pm 0.00$ & $3.66 \pm 0.00$ & 6.40 & 0.57 & $0.12 \pm 0.00$ & $0.36 \pm 0.02$ & 0.49 & 0.87 & 0.14 & 7.3 \\
\hline 10 & $2.34 \pm 0.02$ & $3.01 \pm 0.03$ & 5.35 & 0.56 & $0.16 \pm 0.01$ & $0.28 \pm 0.00$ & 0.44 & 0.94 & 0.13 & 8.4 \\
\hline 11 & $3.43 \pm 0.01$ & $3.68 \pm 0.03$ & 7.11 & 0.52 & $0.26 \pm 0.00$ & $0.36 \pm 0.00$ & 0.62 & 1.34 & 0.13 & 12.0 \\
\hline 12 & $4.18 \pm 0.00$ & $3.94 \pm 0.00$ & 8.12 & 0.49 & $0.27 \pm 0.00$ & $0.34 \pm 0.00$ & 0.61 & 1.71 & 0.15 & 13.3 \\
\hline 13 & $5.41 \pm 0.24$ & $3.45 \pm 0.11$ & 8.86 & 0.39 & $0.42 \pm 0.01$ & $0.28 \pm 0.01$ & 0.69 & 2.62 & 0.16 & 19.1 \\
\hline 14 & $2.41 \pm 0.15$ & $3.96 \pm 0.08$ & 6.37 & 0.62 & $0.14 \pm 0.00$ & $0.40 \pm 0.01$ & 0.55 & 0.63 & 0.11 & 6.7 \\
\hline 15 & $4.09 \pm 0.00$ & $3.46 \pm 0.01$ & 7.55 & 0.46 & $0.50 \pm 0.01$ & $0.31 \pm 0.01$ & 0.82 & 1.96 & 0.15 & 15.2 \\
\hline 16 & $4.75 \pm 0.19$ & $4.01 \pm 0.02$ & 8.76 & 0.46 & $0.53 \pm 0.01$ & $0.37 \pm 0.02$ & 0.90 & 2.62 & 0.18 & 17.0 \\
\hline 17 & $5.19 \pm 0.03$ & $5.55 \pm 0.18$ & 10.76 & 0.52 & $0.15 \pm 0.00$ & $0.43 \pm 0.01$ & 0.58 & 3.33 & 0.30 & 13.0 \\
\hline
\end{tabular}


(b) Continued.

\begin{tabular}{|c|c|c|c|c|c|c|c|c|c|c|}
\hline \multirow{2}{*}{ Loc. } & \multicolumn{4}{|c|}{ Loss on ignition } & \multicolumn{3}{|c|}{ Phosphorus } & \multicolumn{3}{|c|}{ Bulk elemental } \\
\hline & Labile (\%) & Refrac. (\%) & TOM (\%) & $\mathrm{Rp}$ & IP (mg/g) & $\mathrm{OP}(\mathrm{mg} / \mathrm{g})$ & $\mathrm{TP}(\mathrm{mg} / \mathrm{g})$ & $\mathrm{OC}(\%)$ & $\mathrm{TN}(\%)$ & $\mathrm{C} / \mathrm{N}$ \\
\hline 18 & $4.31 \pm 0.01$ & $5.31 \pm 0.01$ & 9.62 & 0.55 & $0.10 \pm 0.01$ & $0.23 \pm 0.01$ & 0.32 & 1.98 & 0.21 & 11.0 \\
\hline 19 & $3.59 \pm 0.05$ & $5.05 \pm 0.02$ & 8.64 & 0.58 & $0.19 \pm 0.01$ & $0.68 \pm 0.00$ & 0.87 & 1.78 & 0.26 & 8.0 \\
\hline 20 & $3.54 \pm 0.04$ & $5.02 \pm 0.02$ & 8.56 & 0.59 & $0.15 \pm 0.00$ & $0.47 \pm 0.01$ & 0.62 & 1.91 & 0.23 & 9.7 \\
\hline 21 & $3.50 \pm 0.00$ & $5.31 \pm 0.01$ & 8.81 & 0.60 & $0.03 \pm 0.00$ & $0.30 \pm 0.02$ & 0.33 & 0.82 & 0.16 & 6.0 \\
\hline LK1 & $14.32 \pm 0.01$ & $7.07 \pm 0.11$ & 21.39 & 0.33 & $0.76 \pm 0.00$ & $0.52 \pm 0.00$ & 1.28 & 9.79 & 0.38 & 30.1 \\
\hline LK2 & $15.60 \pm 0.24$ & $7.69 \pm 0.06$ & 23.29 & 0.33 & $0.76 \pm 0.00$ & $0.58 \pm 0.04$ & 1.34 & 9.55 & 0.49 & 22.7 \\
\hline LK3 & $10.34 \pm 0.04$ & $4.24 \pm 0.04$ & 14.58 & 0.29 & $0.73 \pm 0.02$ & $0.41 \pm 0.07$ & 1.14 & 5.51 & 0.26 & 24.7 \\
\hline MH1 & $7.60 \pm 0.04$ & $5.82 \pm 0.02$ & 13.42 & 0.43 & $0.53 \pm 0.00$ & $0.44 \pm 0.06$ & 0.97 & 3.62 & 0.23 & 18.4 \\
\hline MH2 & $6.45 \pm 0.01$ & $6.27 \pm 0.04$ & 12.72 & 0.49 & $0.46 \pm 0.00$ & $0.42 \pm 0.01$ & 0.87 & 2.71 & 0.18 & 17.6 \\
\hline MH3 & $4.05 \pm 0.06$ & $5.29 \pm 0.04$ & 9.34 & 0.57 & $0.31 \pm 0.00$ & $0.34 \pm 0.01$ & 0.65 & 1.72 & 0.15 & 13.4 \\
\hline
\end{tabular}

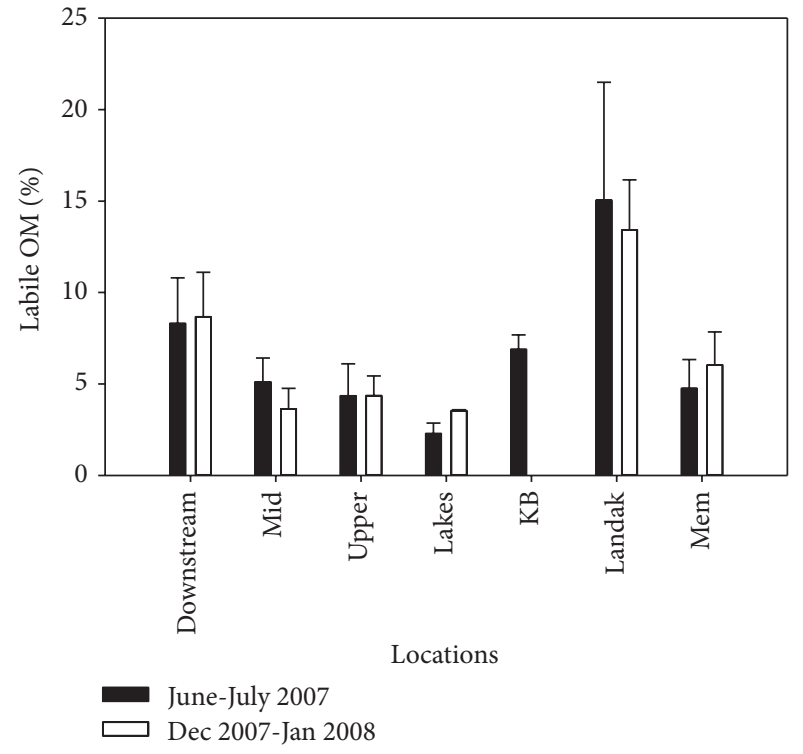

(a)

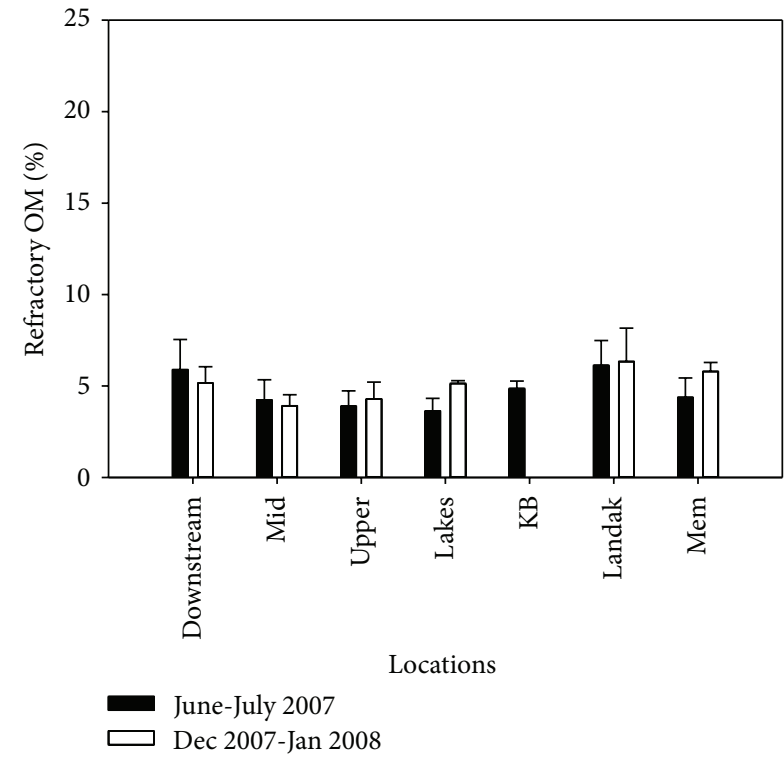

(b)

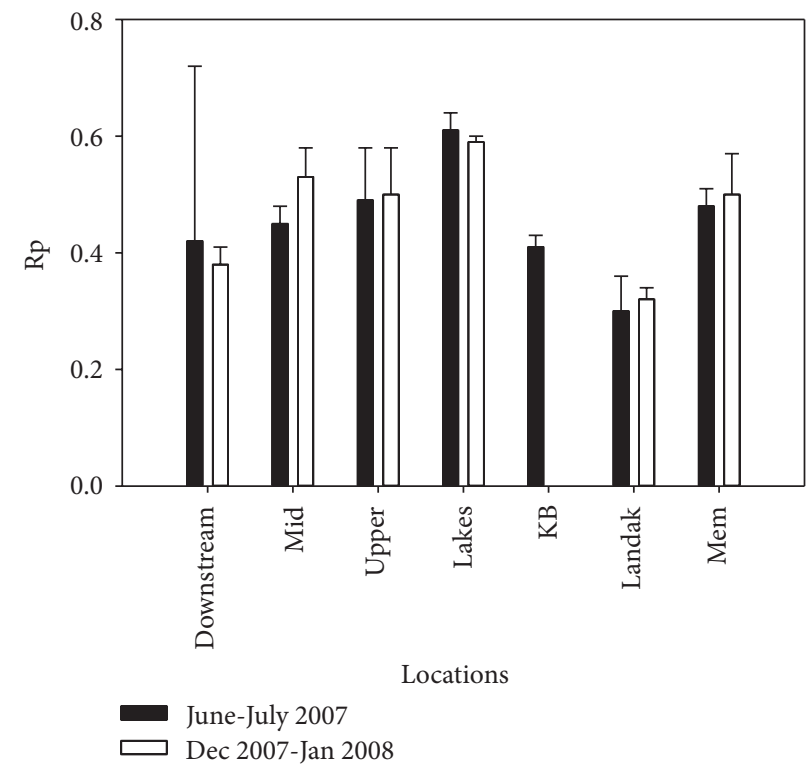

(c)

FIGURE 2: Charts with error bars showing the means and standard deviations for (a) labile OM, (b) refractory OM, and (c) Rp values along the downstream, mid-, and upper Kapuas River, the lakes, Kapuas Besar (KB), and the Landak and Mempawah Rivers (Mem). 


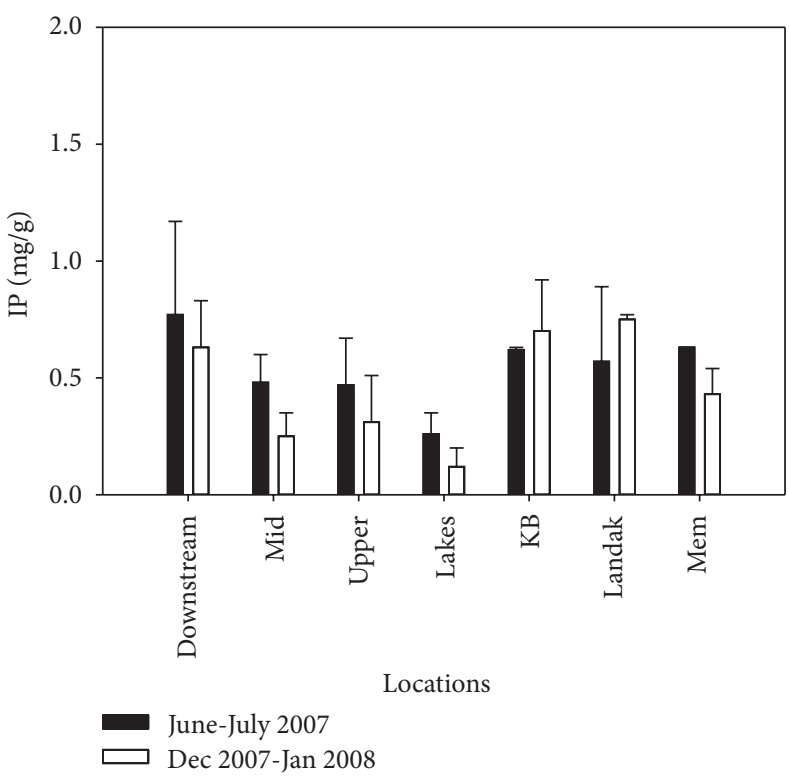

(a)

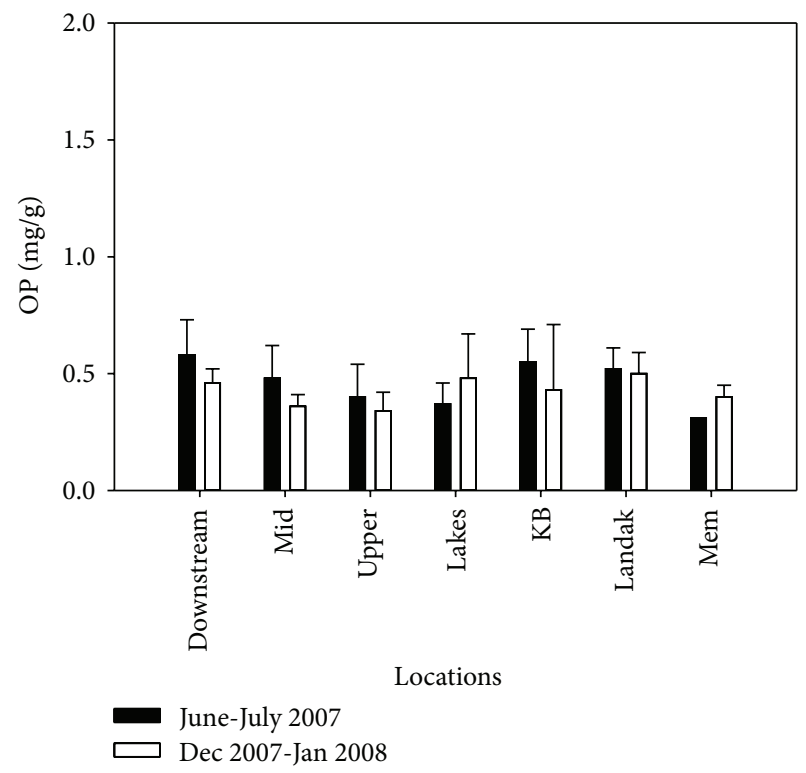

(b)

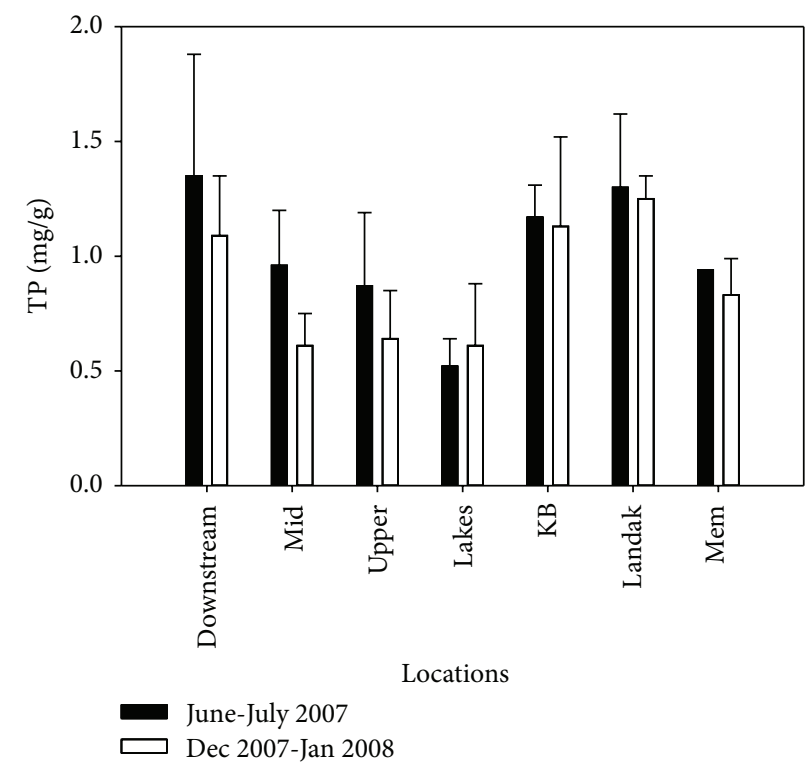

(c)

Figure 3: Charts with error bars showing the means and standard deviations for (a) IP, (b) OP, and (c) TP along the downstream, mid-, and upper Kapuas River, the lakes, Kapuas Besar (KB), and the Landak and Mempawah Rivers (Mem).

The sediment along the stretches of river with the highest population density had the highest IP and OP levels. Hence, we concluded that the sedimentary IP and OP originated from human activities and were discharged into the lower river via fluvial input. Other external sources of $\mathrm{P}$ could be from groundwater, fluvial, and atmosphere [27]. Eutrophication can cause high OM input to sediments, which results in increased sedimentary TC, OC, TN, TP, and OP levels [28], followed by increased decomposition of OM [29]. This sequence of events occurred in the downstream Kapuas River, where the sediment also showed high labile, refractory, and total OM and high OP, IP, and TP (Figures 2 and 3). The midriver, which is surrounded by oil palm plantations, has higher levels of IP and OP than the upper river but lower P levels than the lower Kapuas River. These results show that higher levels of $\mathrm{P}$ are found near the oil palm plantations than in the forested area surrounding the upper river, but the $\mathrm{P}$ level was nonetheless lower than in the downstream portion of the river.

4.3. Dynamics of the Kapuas River. Forests and tributaries are continuous sources of different amounts of carbon to surrounding reaches of a river [30]. OM is delivered in particulate form such as wood fragments and leaves or sometimes bound to mineral surfaces. Factors such as rainfall, runoff, and snowmelt can affect the supply of organic and inorganic 


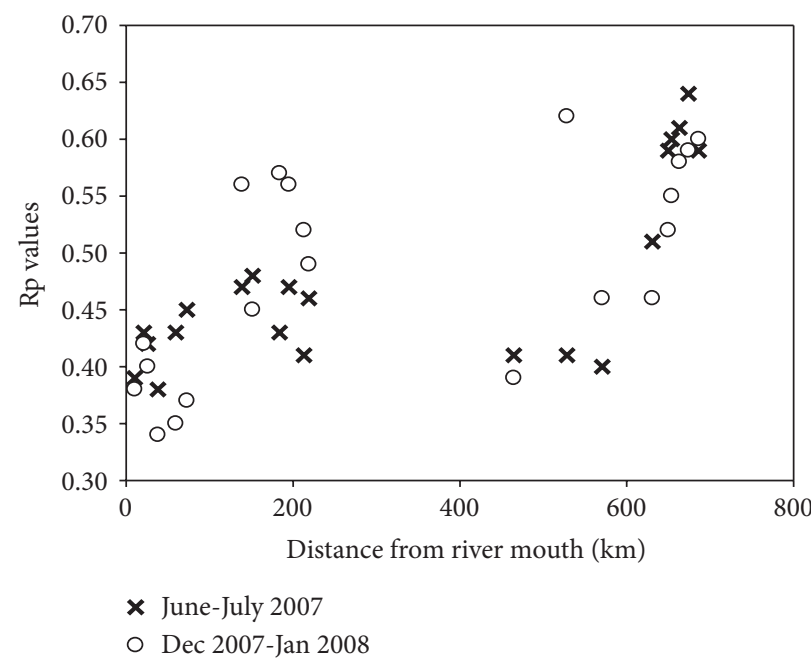

(a)

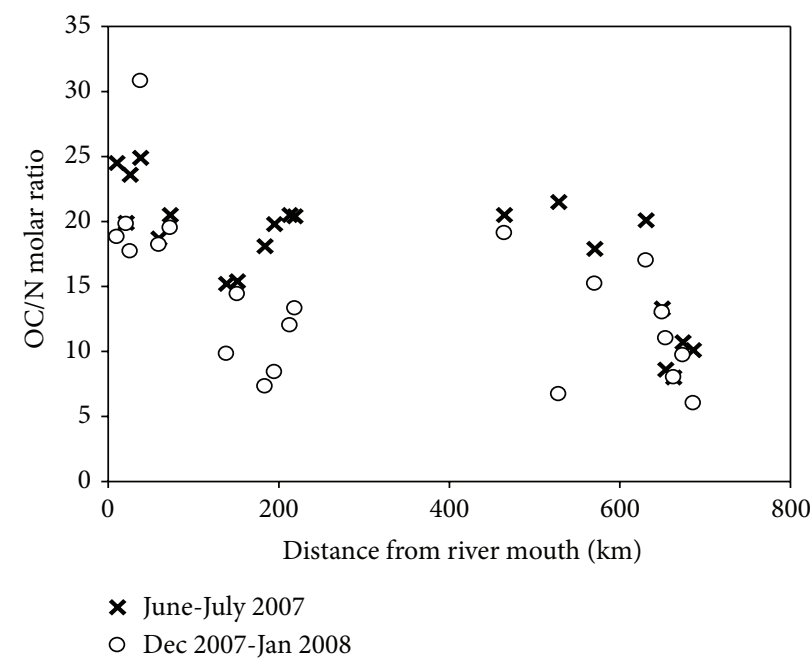

(b)

FIgURE 4: Figure showing the transect profiles of (a) Rp values and (b) TOC/TN molar ratios for samples taken during June-July 2007 and December 2007-January 2008. All the sampling locations numbered from 1 to 21 in Table 1 and Figure 1 are presented in the graph, with location 1 situated nearest to the river mouth and location 21 farthest from the river mouth.

material to sediment [31]. Few studies have determined the levels of $\mathrm{OM}$ and nutrients along a river system. $\mathrm{CO}_{2}$ emissions and the influx of $\mathrm{O}_{2}$ along a river system may be due to respiration activities fuelled by autochthonous $\mathrm{OM}$ [30]; thus, carbon has been found to outgas during transport further downstream [1]. Relatively fresh OM was also a major source of atmospheric $\mathrm{CO}_{2}$ emissions because fresh material has been found to be respired by organisms fairly rapidly, thereby contributing to atmospheric $\mathrm{CO}_{2}$ emissions [2]. In a study of fine particulate OM (FPOM), course particulate OM (CPOM), and dissolved OM (DOM) in upstream and downstream Bolivian tributaries of the Amazon River, it was determined that all fractions became more degraded further downstream [32].

In the upper Kapuas River and lakes, logging activities may have exposed the forest soil, causing elevated aerobic OM degradation. This degraded material was then discharged into the river because of erosion. Due to the discharge of more degraded $\mathrm{OM}$ but less $\mathrm{P}$ into the upper river, we concluded that less OM decomposition occurred in the upper Kapuas River. The midriver, which is surrounded by oil palm plantations, had medium levels of IP and OP compared to the upper and lower Kapuas River and less degraded OM than the upper river. This shows that there were higher levels of $\mathrm{P}$ near the oil palm plantations than near the forested areas surrounding the upper river. The most densely populated areas along the Kapuas River were located along the lower river. A high abundance of fresher sedimentary OM and P in this location may have resulted in increased phytoplankton blooms and high rates of OM decomposition. The Landak River has high levels of labile and refractory OM, low Rp values, and high $\mathrm{P}$ levels, whereas the Mempawah River has low levels of labile and refractory OM, high Rp values, and medium P levels. Hence, the Landak River may be more prone to phytoplankton bloom and OM decomposition than the Mempawah River. Overall, June-July 2007, the period with higher rainfall than December 2007-January 2008 [17], also showed higher IP, OP, and TP for most of the locations (Figure 3), indicating some leaching of $\mathrm{P}$ from soil into the river.

\section{Conclusions}

This study is one of few to use the loss-on-ignition experiment to examine sedimentary OM in terms of labile, refractory, and total $\mathrm{OM}$ and $\mathrm{Rp}$ values and to measure $\mathrm{P}$ levels in the sediment along a complete transect of a tropical river in Southeast Asia. This is also one of the few studies to make further use of the $\mathrm{Rp}$ values and $\mathrm{C} / \mathrm{N}$ ratios developed by Kristensen [19] to determine the sources and diagenesis of sedimentary OM. The highest $\mathrm{P}$ level was located in the downstream Kapuas River, which was the most densely populated area. The next highest $\mathrm{P}$ level was located along the midstream river, which was surrounded by oil palm plantations. The sediment in the upper river, which was surrounded by forest, had the lowest P level. Phytoplankton blooms and high OM decomposition most likely occurred along the downstream Kapuas River where the sediment OM was fresher and more bioavailable and the P level was the highest.

\section{Competing Interests}

The authors declare that they have no competing interests.

\section{Acknowledgments}

The authors wish to thank everyone for their help and advice throughout the course of this study. This study acknowledges the Taiwan National Science Council Research Grants 
NSC101-2611-M-110-010-MY3 and MOST103-2611-M-110-010 and the Aim for the Top University Program Project 03C 0302 04.

\section{References}

[1] J. E. Richey, J. M. Melack, A. K. Aufdenkampe, V. M. Ballester, and L. L. Hess, "Outgassing from Amazonian rivers and wetlands as a large tropical source of atmospheric $\mathrm{CO}_{2}$," Nature, vol. 416, no. 6881, pp. 617-620, 2002.

[2] E. Mayorga, A. K. Aufdenkampe, C. A. Masiello et al., "Young organic matter as a source of carbon dioxide outgassing from Amazonian rivers," Nature, vol. 436, no. 7050, pp. 538-541, 2005.

[3] M. T. H. van Vliet, W. H. P. Franssen, J. R. Yearsley et al., "Global river discharge and water temperature under climate change," Global Environmental Change, vol. 23, no. 2, pp. 450-464, 2013.

[4] M. Floury, C. Delattre, S. J. Ormerod, and Y. Souchon, "Global versus local change effects on a large European river," Science of the Total Environment, vol. 441, pp. 220-229, 2012.

[5] N. W. Arnell and S. N. Gosling, "The impacts of climate change on river flow regimes at the global scale," Journal of Hydrology, vol. 486, pp. 351-364, 2013.

[6] X. X. Lu, L. S. Ran, S. Liu, T. Jiang, S. R. Zhang, and J. J. Wang, "Sediment loads response to climate change: a preliminary study of eight large Chinese rivers," International Journal of Sediment Research, vol. 28, no. 1, pp. 1-14, 2013.

[7] D. J. J. Tysmans, A. J. Löhr, C. Kroeze, W. P. M. F. Ivens, and J. Van Wijnen, "Spatial and temporal variability of nutrient retention in river basins: a global inventory," Ecological Indicators, vol. 34, pp. 607-615, 2013.

[8] J. P. M. Syvitski, C. J. Vörösmarty, A. J. Kettner, and P. Green, "Impact of humans on the flux of terrestrial sediment to the global coastal ocean," Science, vol. 308, no. 5720, pp. 376-380, 2005.

[9] S. E. Page, R. A. J. Wüst, D. Weiss, J. O. Rieley, W. Shotyk, and S. H. Limin, "A record of Late Pleistocene and Holocene carbon accumulation and climate change from an equatorial peat bog (Kalimantan, Indonesia): implications for past, present and future carbon dynamics," Journal of Quaternary Science, vol. 19, no. 7, pp. 625-635, 2004.

[10] J. H. M. Wösten, E. Clymans, S. E. Page, J. O. Rieley, and S. H. Limin, "Peat-water interrelationships in a tropical peatland ecosystem in Southeast Asia," Catena, vol. 73, no. 2, pp. 212-224, 2008.

[11] M. Alkhatib, T. C. Jennerjahn, and J. Samiaji, "Biogeochemistry of the Dumai River estuary, Sumatra, Indonesia, a tropical blackwater river," Limnology and Oceanography, vol. 52, no. 6, pp. 2410-2417, 2007.

[12] A. Baum, T. Rixen, and J. Samiaji, "Relevance of peat draining rivers in central Sumatra for the riverine input of dissolved organic carbon into the ocean," Estuarine, Coastal and Shelf Science, vol. 73, no. 3-4, pp. 563-570, 2007.

[13] T.-H. Huang, Y.-H. Fu, P.-Y. Pan, and C.-T. A. Chen, "Fluvial carbon fluxes in tropical rivers," Current Opinion in Environmental Sustainability, vol. 4, no. 2, pp. 162-169, 2012.

[14] C. Freeman, C. D. Evans, D. T. Monteith, B. Reynolds, and N. Fenner, "Export of organic carbon from peat soils," Nature, vol. 412, no. 6849, p. 785, 2001.
[15] L. J. Tranvik and M. Jansson, “Terrestrial export of organic carbon,” Nature, vol. 415, pp. 861-862, 2002.

[16] H.-K. Lui and C.-T. A. Chen, "The nonlinear relationship between nutrient ratios and salinity in estuarine ecosystems: implications for management," Current Opinion in Environmental Sustainability, vol. 4, no. 2, pp. 227-232, 2012.

[17] P. S. Loh, C.-T. A. Chen, G. Z. Anshari, J.-T. Wang, J.-Y. Lou, and S.-L. Wang, "A comprehensive survey of lignin geochemistry in the sedimentary organic matter along the Kapuas River (West Kalimantan, Indonesia)," Journal of Asian Earth Sciences, vol. 43, no. 1, pp. 118-129, 2012.

[18] P. S. Loh, C.-T. A. Chen, J.-Y. Lou, G. Z. Anshari, H.-Y. Chen, and J.-T. Wang, "Comparing lignin-derived phenols, $\delta^{13} \mathrm{C}$ values, $\mathrm{OC} / \mathrm{N}$ ratio and ${ }^{14} \mathrm{C}$ age between sediments in the Kaoping (Taiwan) and the Kapuas (Kalimantan, Indonesia) Rivers," Aquatic Geochemistry, vol. 18, pp. 141-158, 2012.

[19] E. Kristensen, "Characterization of biogenic organic matter by stepwise thermogravimetry (STG)," Biogeochemistry, vol. 9, no. 2, pp. 135-159, 1990.

[20] E. Kristensen and F. $\varnothing$. Andersen, "Determination of organic carbon in marine sediments: a comparison of two CHNanalyzer methods," Journal of Experimental Marine Biology and Ecology, vol. 109, no. 1, pp. 15-23, 1987.

[21] R. A. Sutherland, "Loss-on-ignition estimates of organic matter and relationships to organic carbon in fluvial bed sediments," Hydrobiologia, vol. 389, pp. 153-167, 1998.

[22] J. D. Strickland and T. R. Parsons, A Practical Handbook of Seawater Analysis, Bulletin 167, Fisheries Research Board of Canada, Ottawa, Canada, 2nd edition, 1972.

[23] K. I. Aspila, H. Agemian, and A. S. Y. Chau, "A semi-automated method for the determination of inorganic, organic and total phosphate in sediments," Analyst, vol. 101, no. 1200, pp. 187-197, 1976.

[24] F. Koroleff, Methods of Seawater Analysis, Edited by K. Grasshoff, Verlag Chemie, 1976.

[25] G. Z. Anshari, A. P. Kershaw, and S. van der Kaars, "A Late Pleistocene and Holocene pollen and charcoal record from peat swamp forest, Lake Sentarum wildlife reserve, West Kalimantan, Indonesia," Palaeogeography, Palaeoclimatology, Palaeoecology, vol. 171, no. 3-4, pp. 213-228, 2001.

[26] G. Anshari, A. P. Kershaw, S. van der Kaars, and G. Jacobsen, "Environmental change and peatland forest dynamics in the Lake Sentarum area, West Kalimantan, Indonesia," Journal of Quaternary Science, vol. 19, no. 7, pp. 637-655, 2004.

[27] S. Moore, C. D. Evans, S. E. Page et al., "Deep instability of deforested tropical peatlands revealed by fluvial organic carbon fluxes," Nature, vol. 493, no. 7434, pp. 660-663, 2013.

[28] K. Łukawska-Matuszewska, J. Kiełczewska, and J. Bolałek, "Factors controlling spatial distributions and relationships of carbon, nitrogen, phosphorus and sulphur in sediments of the stratified and eutrophic Gulf of Gdansk," Continental Shelf Research, vol. 85, pp. 168-180, 2014.

[29] V. H. Smith, G. D. Tilman, and J. C. Nekola, "Eutrophication: impacts of excess nutrient inputs on freshwater, marine, and terrestrial ecosystems," Environmental Pollution, vol. 100, no. 13, pp. 179-196, 1999.

[30] J. E. Richey, J. I. Hedges, A. H. Devol et al., "Biogeochemistry of carbon in the Amazon River," Limnology and Oceanography, vol. 35, no. 2, pp. 352-371, 1990. 
[31] R. S. Adams and R. M. Bustin, "The effects of surface area, grain size and mineralogy on organic matter sedimentation and preservation across the modern Squamish Delta, British Columbia: the potential role of sediment surface area in the formation of petroleum source rocks," International Journal of Coal Geology, vol. 46, no. 2-4, pp. 93-112, 2001.

[32] J. I. Hedges, E. Mayorga, E. Tsamakis et al., "Organic matter in Bolivian tributaries of the Amazon river: a comparison to the lower mainstream," Limnology and Oceanography, vol. 45, no. 7, pp. 1449-1466, 2000. 

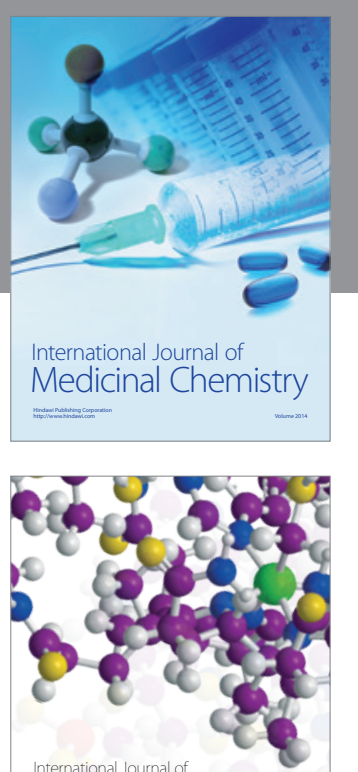

Carbohydrate Chemistry

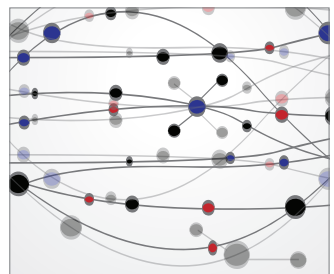

The Scientific World Journal
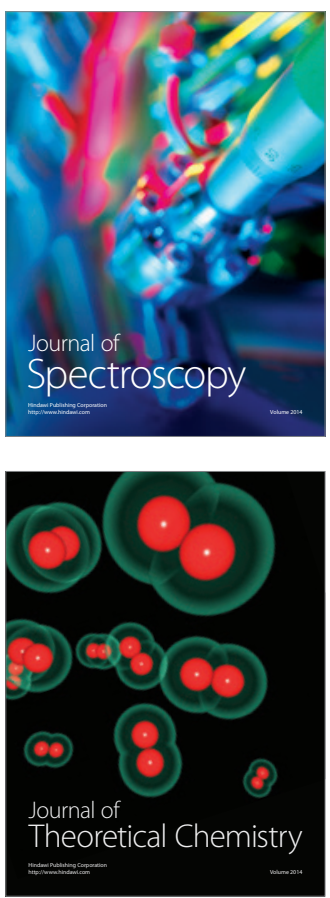
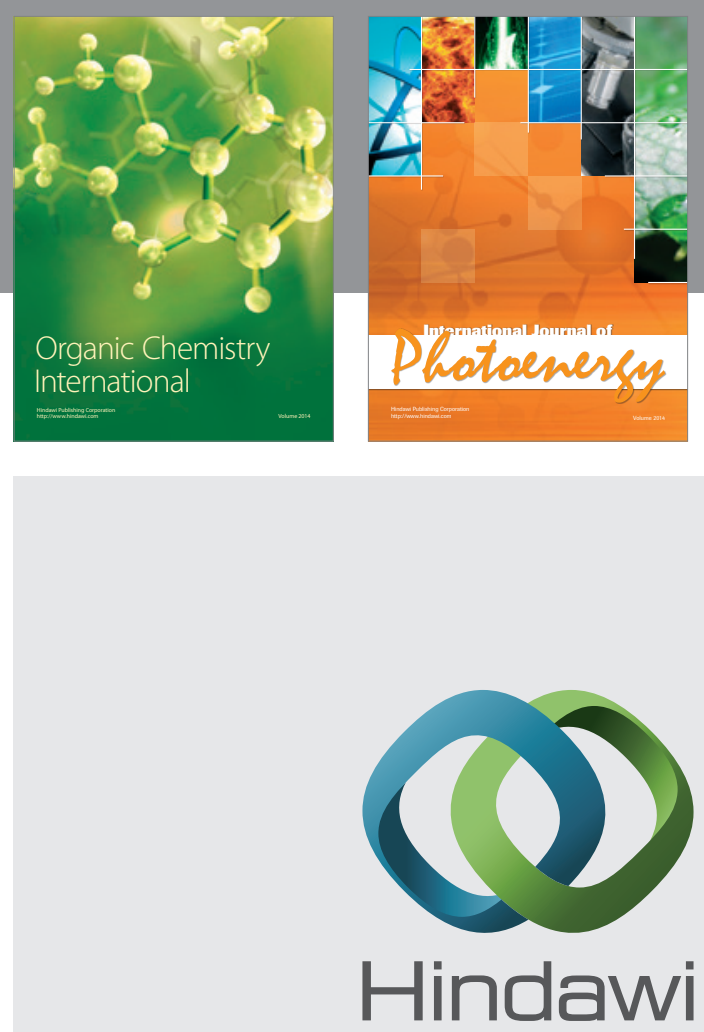

Submit your manuscripts at

http://www.hindawi.com

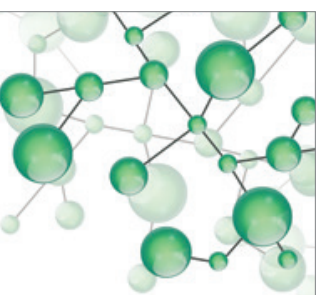

International Journal of

Inorganic Chemistry

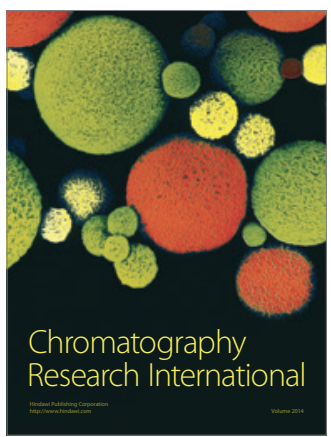

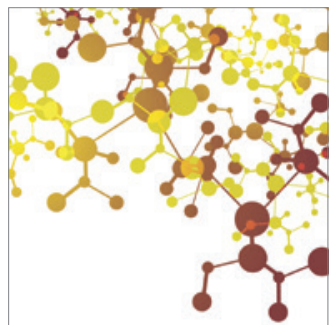

Applied Chemistry
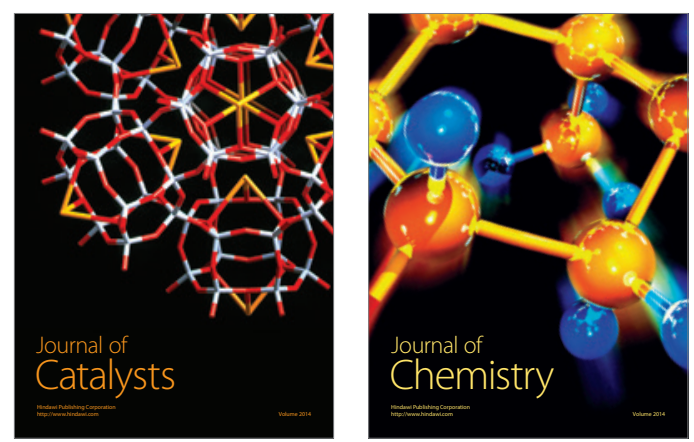
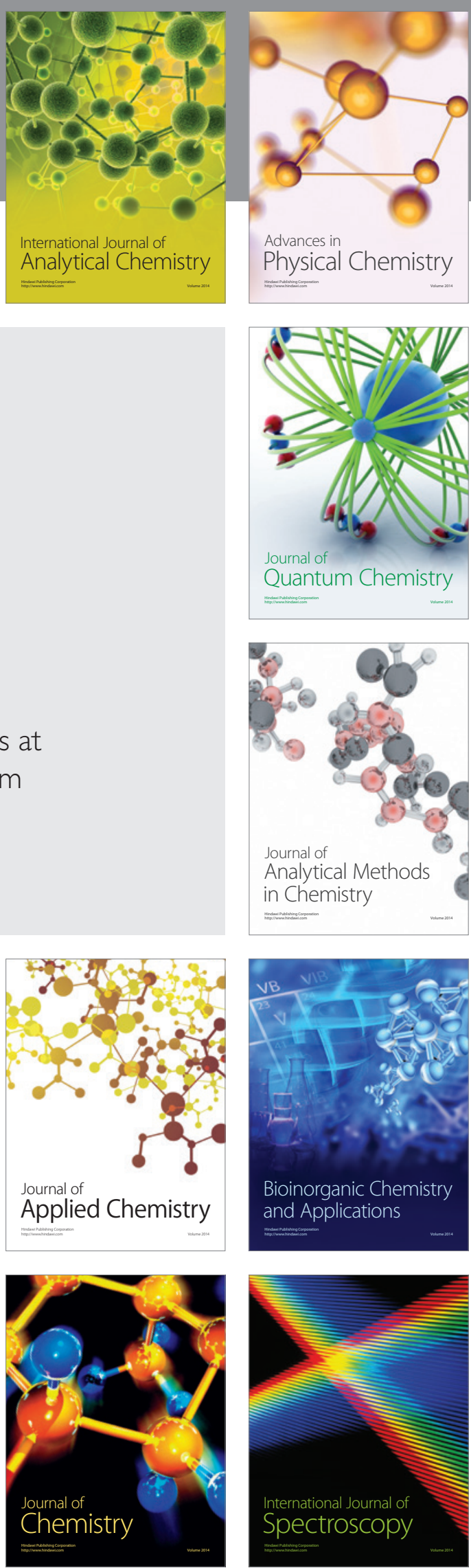